\title{
Maximum Power Extraction Strategy for Wind Energy Conversion Systems using Intelligent Controllers
}

\author{
Aabid Hussain Sheikh \\ Department of Electrical \& Electronics \\ Engineering, AL-Falah University of Engineering \\ \& Technology, India
}

\author{
Dr O P Malik \\ Professor, Department of Electrical \& Electronics \\ Engineering, AL- Falah University of Engineering \\ \& Technology, India
}

\section{ABSTRACT}

This paper proposes a sway strategy to optimize power output performance of wind energy conversion system. so as to get optimum power output from a turbine generator system, it's necessary to drive the turbine at Associate in Nursing optimum rotor speed for a specific wind speed. Symbolic logic based mostly management algorithmic rule is enforced with the embedded microcontroller which can track the utmost wall socket (MPP) by generating acceptable generator load references. The designed controller then forces the system to work towards the settled load reference. This paper discusses the low value implementation of symbolic logic based mostly MPP algorithmic rule in an exceedingly 8-bit microcontroller victimization the tools and techniques to get optimized real time code in $\mathrm{C}$ which can demonstrate however most wall socket hunter would possibly offer elegant and economical resolution for increasing the potency of wind energy conversion systems, supported experimental results instead of on mathematical models. The planned construct is verified and results are bestowed.

Keywords:

MPPT Control, Wind energy system, Fuzzy logic, $\mathrm{DC} / \mathrm{DC}$ boost converter, Microcontroller

\section{INTRODUCTION}

As energy sources square measure depleting because of the energy desires of the planet, energy sources square measure being wanted. The explore for clean and low value energy alternatives has yielded wind energy as a wonderful candidate against standard fuel primarily based power generation. Massive turbine primarily based grid connected wind farms have tested to be an ad success in Europe and North America. Little wind energy conversion systems (WECS) square measure potential candidates for remote and off-grid power generation in standalone or hybrid applications [1]. This paper proposes a sway strategy to optimize power output performance of a permanent-magnet synchronous generator (PMSG) beneath variable wind speed, fixed-pitch wind turbines while not the mechanics controls. so as to get optimum power output from a turbine generator system, it's necessary to drive the turbine at associate degree optimum rotor speed for a selected wind speed. Wind rotor performance is fastened for fixed-pitch variable-speed turbine. So, the restoring torsion has to be adjusted to keep up optimum rotor speed at a selected wind speed to get most mechanics power output. Since, the restoring torsion is proportional to generator load current $(\mathrm{TG}=\mathrm{f}(\mathrm{IG}))$, So, the operate of most electric outlet hunter is to produce the desired load on the generator [2].

To implement most wind generation extraction, most controller styles of the variable speed turbine generators use mechanical sensors, polynomial to approximate the turbine power constant, applied mathematics model to predict the wind speed, search table primarily based mapping, looking strategies. These strategies will increase the price, scale back the responsibleness, complicated and time overwhelming calculation, signicant memory house, long looking time severally to find the utmost electric outlet [3].

This paper proposes calculation of acceptable generator load references to get most power by activity frequency of generator victimization frequency sensing element. The designed controller then forces the system to control towards the set load reference.

The projected system includes a PMSG, a PWM controlled DC-DC device and sensing element circuits as shown in Fig. 3. The designed controller regulates the device output load in line with MPP load reference by variable duty cycle of the PWM signal applied to spice up DC-DC device. Mathematical logic is enforced on MPPT algorithmic program for swift most electric outlet trailing to avoid energy loss [4]. 


\section{AERODYNAMIC CHARACTERISTICS OF THE ROTOR}

A wind turbine is characterized by its power-speed characteristics. The power facility extracted from a wind turbine is a function of the wind power available, the power curve of the machine and the ability of the machine to react to wind variations. The power extracted from the wind can be expressed as given by (1) [5].

$$
\begin{aligned}
& P_{m}= 1 C_{P} \rho A V W 3 \\
& 2
\end{aligned}
$$

Where, $\rho$ is the air density, A is the swept area of the turbine and $\mathrm{Vw}$ is the wind velocity. The $\mathrm{Cp}$ parameter is called the power coefficient. The power coefficient is the ratio of the mechanical power at the turbine shaft to the power available in the wind, given as a function of tip speed- ratio as given in (2).

$$
\frac{\text { tip speed of rotor blades }}{\text { wind speed }}=\frac{7 m R}{V_{x}}
$$

Where $\mathrm{R}=$ radius of blades, $\mathrm{m}=$ angular velocity. Power coefficient $\mathrm{CP}$ versus tip speed ratio relationship of the wind turbine is shown in Fig. 1. The maximum power coefficient $\mathrm{Cp}$-max is the optimal tip speed ratio opt. Hence for a given wind speed the available rotor power can be plotted verses the alternator frequency, this is done for variable wind speed, as shown in Fig. 2. In order to extract peak power, the rotor must be held at its optimal tip speed ratio. Clearly the turbine speed should be changed with wind speed so that optimum tip speed ratio is maintained.

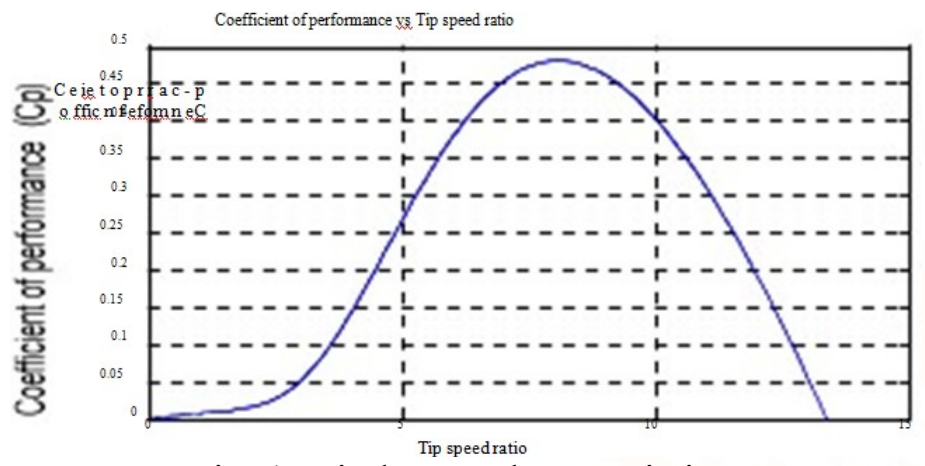

Fig. 1 Wind rotor characteristics

Since rotor angular speed is proportional to the generator frequency, at optimum tip speed quantitative relation, the utmost offered rotor power conjointly varies because the cube of the generator frequency for an equivalent rotor-generator combination. the utmost power from a turbine will be written in the form of equation.

\section{MAXIMUM POWER POINT TRACKING}

The generator torsion is controlled with the optimum torsion curve as shown in Fig. four in line with the generator frequency by varied the effective electrical load on the generator. we tend to assume that the load power is set by the curve marked 'sp, as given in Fig. a pair of which the wind speed is $8.4 \mathrm{~m} / \mathrm{s}$. The rotary engine are in operation at purpose ' $\mathrm{s}$ '. If the wind speed will increase to ten. $4 \mathrm{~m} / \mathrm{s}$, the rotary engine torsion exceeds the load torsion and therefore the rotary engine accelerates toward point ' $p$ '. however now isn't most wall socket for this wind speed. If the load on the generator is forced to increase, the load power can increase, inflicting the rotary engine to slow down. The new operating point would then be point ' $m$ '.

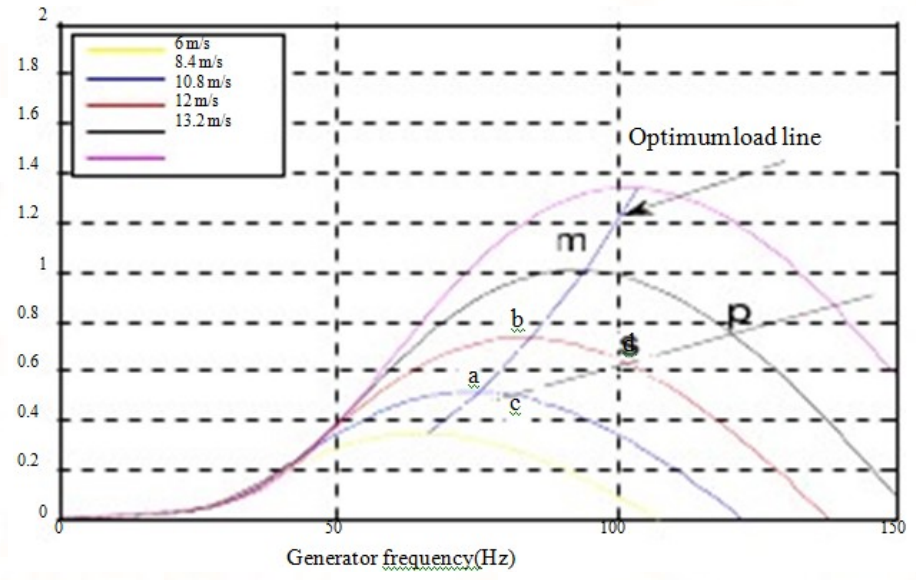

Fig. 2 Wind turbine maximum available rotor power (optimal load curve) and rotor power curve for changing wind speed.

To reach most wall plug for this wind speed, the accelerating/de-accelerating force is calculated from the difference between the rotary engine mechanical force and therefore the torque given by the optimum curve as shown in Fig. 4. Hence the effective load is calculated and operated according to this load. Finally, the generator can reach the point " $\mathrm{m}$ " wherever the fast force is zero. So $(1-.6=0.4 \mathrm{pu})$ power are going to be additional extracted mistreatment MPPT. A similar scenario happens if the wind rate decreases. 


\section{FUZZY LOGIC IMPLEMENTATION}

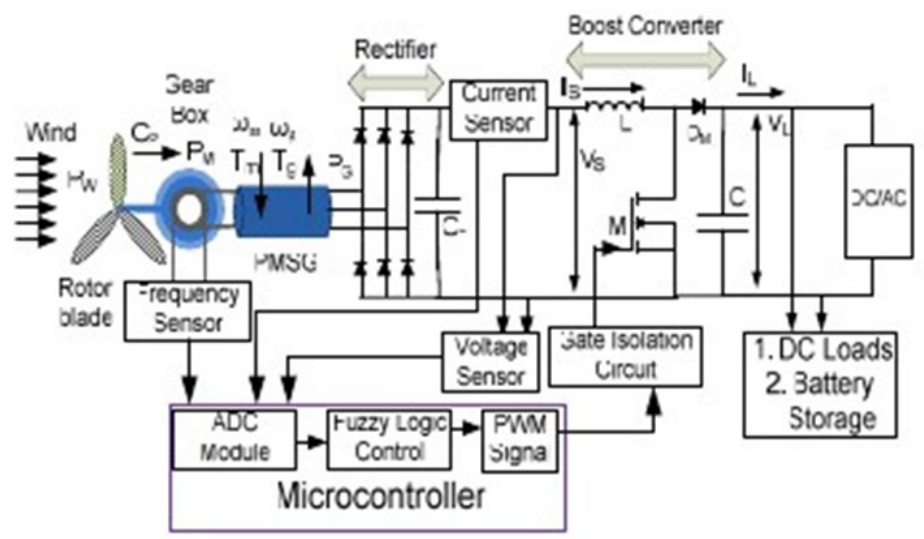

Fig. 3 Control structure of a PMSG-based stand-alone variable speed wind turbine

Fuzzy logic controllers have the benefits of operating with general inputs, not required AN correct mathematical model, handling nonlinearity [6]. For dominant such a sophisticated system, FLC appearance terribly promising for this application. The inputs to a MPPT formal logic controller square measure sometimes a slip-up $E$ and a modification of error $\mathrm{E}$ as given in (4) and (5) severally.

$E(n)=I r e f-I d$

$\delta E(n)=E(n)-E(n-1)$

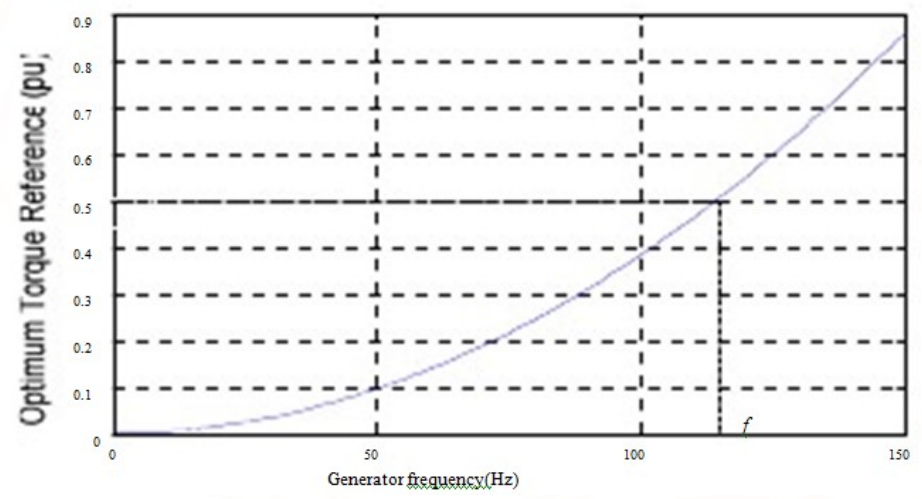

Fig.4 Generator torque reference versus frequency

Where Iref is calculated by measure the rectifier output voltage venereal disease, , i.e. $\operatorname{Iref}=\mathrm{Tg} \times \mathrm{W} / \mathrm{Vd}$ ). Reference force $\mathrm{Tg}$ is calculated by mistreatment optimum power curve as shown in Fig. 4. E and delta $\mathrm{E}$ are calculated and regenerate to the linguistic variables throughout fuzzification. Linguistic variables are nonprecise variables that usually convey a stunning quantity of knowledge. Fig. five shows the relations between measured error and therefore the linguistic term, like positive little, positive medium and positive massive. At some purpose the error is positive little and at some purpose the error is positive massive the house between positive massive and positive little indicates a mistake that's, to a point, to a small degree of each. The horizontal axis within the following graph shows the measured or crisp worth of error. The vertical axis describes the degree to that a linguistic variable fits with the crisp measured knowledge.

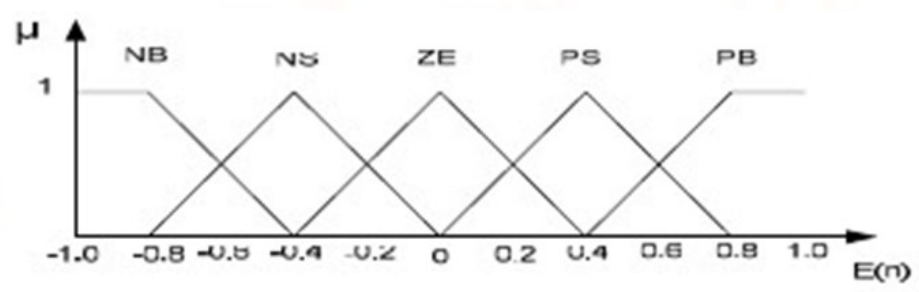

Fig. 5 The relationship between linguistics variable and error

To add the linguistics variable positive big to a computer program running in an embedded microcontroller, translation the graphical representation into meaningful code is needed. The following $\mathrm{C}$ code fragment gives one example of how to do this. The function error- Positive Big () returns a degree of membership, scaled between 0 and 1 , indicating the degree to which a given error can be positive big. This type of simple calculation is the first tool required for calculations of fuzzy logic operations.
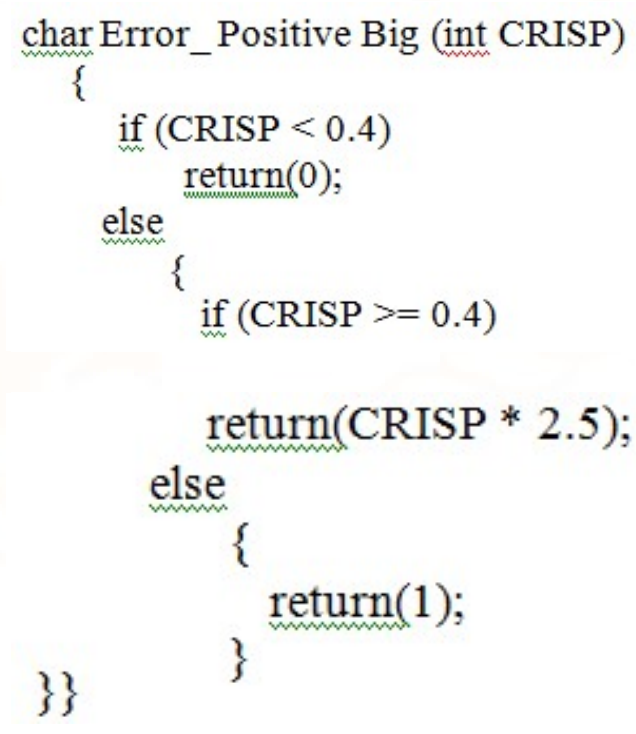
Rule evaluation is done by using an algorithm where loops compare the antecedent value depending on the rule being evaluated in a repeated fashion until all rules are evaluated.

The fuzzy logic controller output is typically a change in duty ratio delta $\mathrm{D}$ of the power converter. The linguistic variables assigned to delta $\mathrm{D}$ for the different combinations of $\mathrm{E}$ and delta $\mathrm{E}$ as shown in Table 1 which is based on a boost converter.

TABLE I

FUZZY RULE BASE TABLE

\begin{tabular}{|l|l|l|l|l|l|}
\hline E & NB & NS & ZE & PS & PB \\
\hline NB & NB & NS & NS & ZE & ZE \\
\hline NS & NB & NS & NS & ZE & PS \\
\hline ZE & NS & NS & ZE & PS & PS \\
\hline PS & NS & ZE & PS & PS & PB \\
\hline PB & ZE & ZE & PS & PS & PB \\
\hline & & & & & \\
\hline
\end{tabular}

The final step within the formal logic controller is to mix the fuzzy output into a crisp systems output. The results of the defuzzification needs to be a numeric worth that determines the modification of duty cycle of the PWM signal wont to drive the MOSFET. There area unit numerous ways to calculate the crisp output of the system. Centre of Gravity (COG) methodology is employed in our application thanks to higher results it provides. The COG for our application is expressed mathematically as given in (6).

$$
\delta D=\frac{\int_{n=1}^{4} Y[i] \cdot F[i]}{f_{n=1}^{4} Y[i]}
$$

Where $\mathrm{Y}[\mathrm{i}]$ is the ith members of the output vector and $\mathrm{F}[\mathrm{i}]$ are the multiplying coefficients of the output membership function as shown in Table 1, and "D is the change of duty cycle, and this number represents a signed number which is added or subtracted from the present duty cycle to generate the next system response for reaching the MPP as given by (7).

Dnew $=$ Dold $+\delta D$
Fuzzy control output surface using Matlab/Simulink simulation is shown in Fig. 6 which represents the change of duty cycle for corresponding error and change of error.

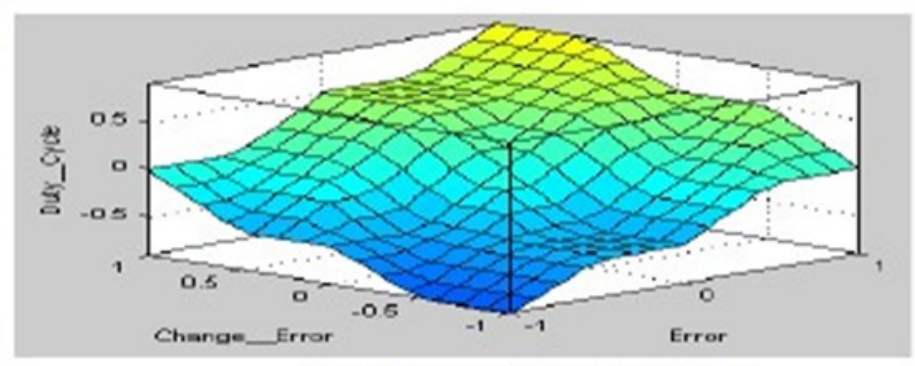

Fig. 6 Fuzzy control output surface

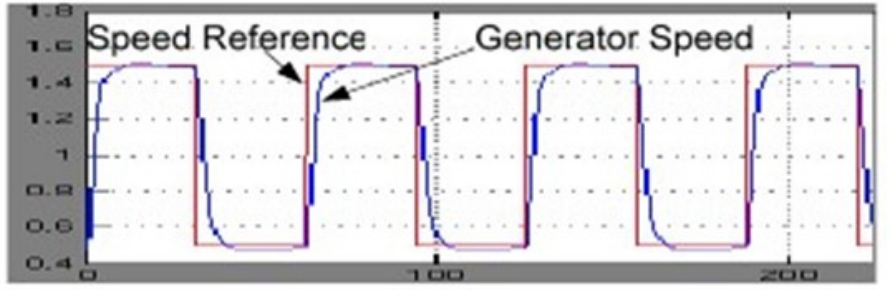

Fig. 7: System performance wind speed step change

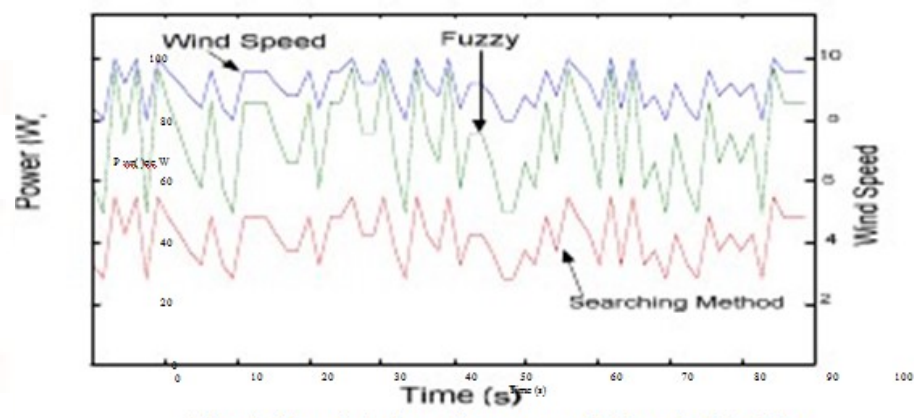

Fig. 8 Simulated performance of the wind turbine

\section{RESULT}

The designed controller is capable of rapidly locking into the maximum power point under variable wind speed. The model of the system together with FLC based mostly MPPT algorithmic rule as shown in Fig. nine is established victimisation Matlab/Simulink and microcontroller based mostly hardware implementation. The system response to step changes in wind speeds is simulated to look at the response of the MPPT controller. As shown in Fig. 7, the step amendment in wind speed the system includes a smart dynamic response. Hardware implementation of fuzzy based mostly gate signal management for everchanging input is shown in Fig. 10. With the given wind speed information, energy output over 100s is simulated. Results show that, system with symbolic logic controller performs higher than looking 
methodology. Simulated performance is shown in Fig. 8 .

\section{CONCLUSION}

The use of fuzzy logic in gate signals management in MPPT is tackled, analyzed, and enforced during this paper wherever Matlab/Simulink simulation and experimental results square measure delineated. The results show however well this controller eliminates the complexness and maximizes the facility extracted from the wind turbine and delivered to the load.

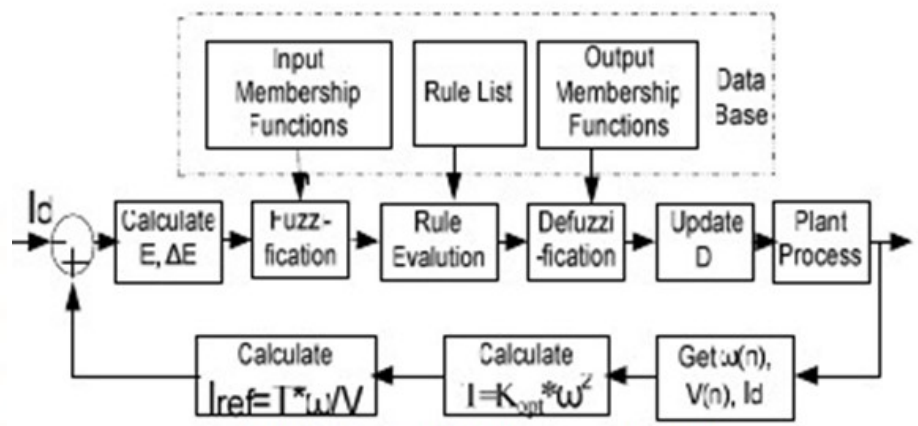

Fig. 9 Fuzzy MPPT firmware algorithm

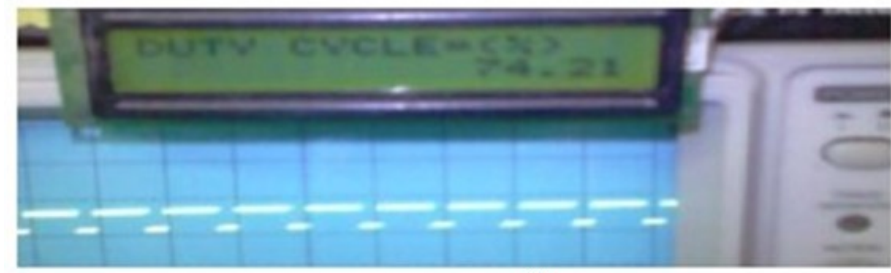

(a)

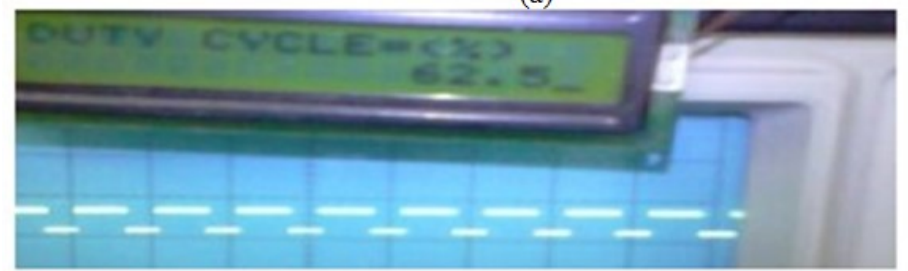

(b)

Fig. 10 Photos of MPPT controlled gate signal, (a) Output gate signal of MPPT controller (b) Tuned fuzzy MPPT controlled gate signal for changed input.

\section{REFERENCES}

[1] M. J. Khan, and M. T. Iqbal, "Dynamic Modeling, Simulation and Control of a Small Wind Energy Conversion System," Proceedings of the International Conference on Mechanical Engineering, Dhaka, Bangladesh, 26- 28 December 2003
[2] E. Muljadi, K. Pierce, P. , "Soft-control control for variable-speed stall-regulated wind turbines", Wind Engineering, Vol.85, pp277-291, Migliore, 2000

[3] Wei Qiao, Wei Zhou, José M. Aller, and Ronald G. Harley "Wind Speed Estimation Based Sensorless Output Maximization Control for a Wind Turbine Driving a DFIG," IEEE Trans. Power Electron, vol.23, no.3, pp. 1156-1169, May 2008

[4] Simoes, M.G.; Bose, B.K.; Spiegel, R.J.; "Design and performance evaluation of a fuzzy-logic-based variable-speed wind generation system" IEEE Trans. On Industry Applications, Vol. 33, no. 4, pp. 956 965, July-Aug. 1997.

[5] D Le. Gourieres, Wind Power Plants Theory and Design, Oxford: Pergamon press, pp76-120, 1982.

[6] Bor-Sen Chen, Chung-Shi Tseng and Huey-Jian Uang, "Robustness Design of Nonlinear Dynamic Systems via Fuzzy Linear Control," IEEE Fuzzy Systems, vol. 7, no. 5, pp. 571-585, Oct. 1999. 